The illustrations and bibliographies that accompany the lectures are excellent and the work should prove of considerable use to those of us who, although not neurologists, feel the need of some simple account of modern neurological methods and ideas. We regret that it should not have been possible to issue such a very brief work at a lower price.

\title{
CORRESPONDENCE
}

\section{NOTES OF A CASE OF KERATITIS FOLLOWING MUMPS}

To the Editor of The British Journal of OpHithalmology

Sir,-On April 14, 1927, I saw a woman, aged 29 years. She had contracted mumps fourteen days before and the eye condition started four days before I saw her, though there had been discomfort in the eye for five days. The right eye only was affected, and she was still in bed with mumps. At first sight it seemed a typical interstitial keratitis. The right eye was red and watery, with very little pain. Ciliary injection very marked. The whole right cornea was cloudy with interstitial opacity and there was marked "striate keratitis." The iris appeared not to be involved and the aqueous was perfectly transparent. The iris dilated rapidly under homatropine and cocaine. Vision : right $1 / 60$; left $6 / 6$.

Tension normal, and no tenderness on feeling tension, indeed no complaints of pains of any kind; no fundus reflex. Wassermann negative. Left eye normal externally and internally. Five days later the condition was very much improved, the cornea being nearly clear, with hardly any ciliary injection. Fundus normal. $\mathrm{V} .=6 / 24$. Thirteen days after I first saw her (17 days from onset) traces of ciliary injection, cornea perfectly transparent, iris normal; indeed a normal eye with visual acuity of $6 / 6$. The patient was seen on September 25, when everything was found to be satisfactory.

I remained completely "at sea" as to the nature of the case until I read the note in the Brit. Jl. of Ophthal. of July, 1927, when it was apparent that it was an exactly similar type of case to that recorded.

Aldershot, Yours truly,

J. Biggam, Major, R.A.M.C.

September, 1927. 